\title{
A Modern Lightning Discharge Counter
}

\author{
Willitam W. Seemuller ${ }^{1}$ and Ferdinand H. Zegel ${ }^{2}$ \\ Weather Bureau, ESSA, Silver Spring, Md.
}

(Manuscript received 2 October 1967, in revised form 18 March 1968)

\begin{abstract}
Design details and test results are given for a transistorized lightning discharge counter updating the Sullivan-Wells UF/FC-2C counter. Particular attention was given in the design to reliability and elimination of multiple counts.

The nature of the signal from a cloud-to-ground discharge induced on a ball antenna was determined. This result was used as the basis of the design of the counter. Tests were made to determine sensitivity, stability (as related to temperature and battery voltage fluctuation), susceptibility to stray counts, and susceptibility to multiple counts. Tests revealed that the transistorized counter is superior to the UF/FC-2C vacuum tube counter in all the above categories except temperature stability, where the vacuum tube counter is less sensitive to changes in ambient temperature. The counter is a device suitable for detecting storms outside the range of human observation, and for indicating relative storm activity within a specified radius.
\end{abstract}

\section{Introduction}

The U. S. Weather Bureau has employed a slightly modified version of the basic "Sullivan-Wells" lightning stroke counter in its Automatic Meteorological Observation Station (AMOS) program (Sullivan and Wells, 1957; Zegel, 1964). These lightning-induced field-change detectors are low frequency $(10 \mathrm{kHz})$, broadband $(2-40$ $\mathrm{kHz}$ ) vacuum tube sferic receivers, and they have been used at various AMOS locations for the past ten years. While the unit has been satisfactory as a detection device, it has proved inaccurate in determining relative storm severity and it lacks long term reliability. The particular difficulties with the original counter involved: 1) multiple counts (Two or more individual strokes would register if the main flash lasted longer than the receiver repetition rate. It is desired to measure only the unique occurrence of the complete discharge);2) relay failure, necessitating frequent replacement; 3) ac line-voltage surges causing false counts; and 4) runaway counting rates during times of high electric field (corona discharges). In an effort to overcome these difficulties the Sullivan-Wells circuit was modified. The new circuit is entirely transistorized and employs no mechanical relays. In addition to overcoming the difficulties cited above, the new unit has the advantages of smaller volume, lower power consumption and greater sensitivity.

\section{Instrument design}

a. Basic counter design

The counter design was based upon the results from an analysis of the natur: of the electrical signal caused

\footnotetext{
I Present affiliation: Electrical Engineering Department, University of Virginia, Charlottesville.

2 Present affiliation: National Environmental Satellite Center, ESSA, Suitland, Md.
}

by a cloud-to-ground lightning discharge; the body of data was taken from published material (e.g., Schonland, 1953, 1956) and from recent experiments conducted by the Weather Bureau (unpublished). Although it is desired to count only cloud-to-ground discharges [since it is these that cause the havoc to life and property (Zegel 1967)], it cannot be achieved in an inexpensive design.

A single discharge may have a duration $\geqslant 1 \mathrm{sec}$ and may have many discrete field-change steps (individual strokes). Fig. 1a shows a typical electric field-change caused by a cloud-to-ground lightning discharge. The average rise time for a single step is about $20 \mu \mathrm{sec}$.

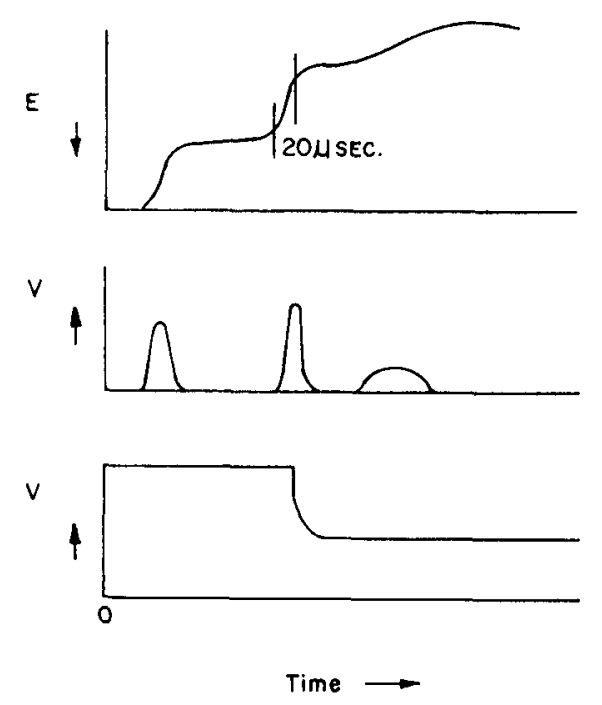

Frg. 1. Electric field characteristics due to lightning: change in earth's electric field due to a lightning discharge, a., electric field as differentiated by a ball antenna, b., and lightning counter response, $c$. 


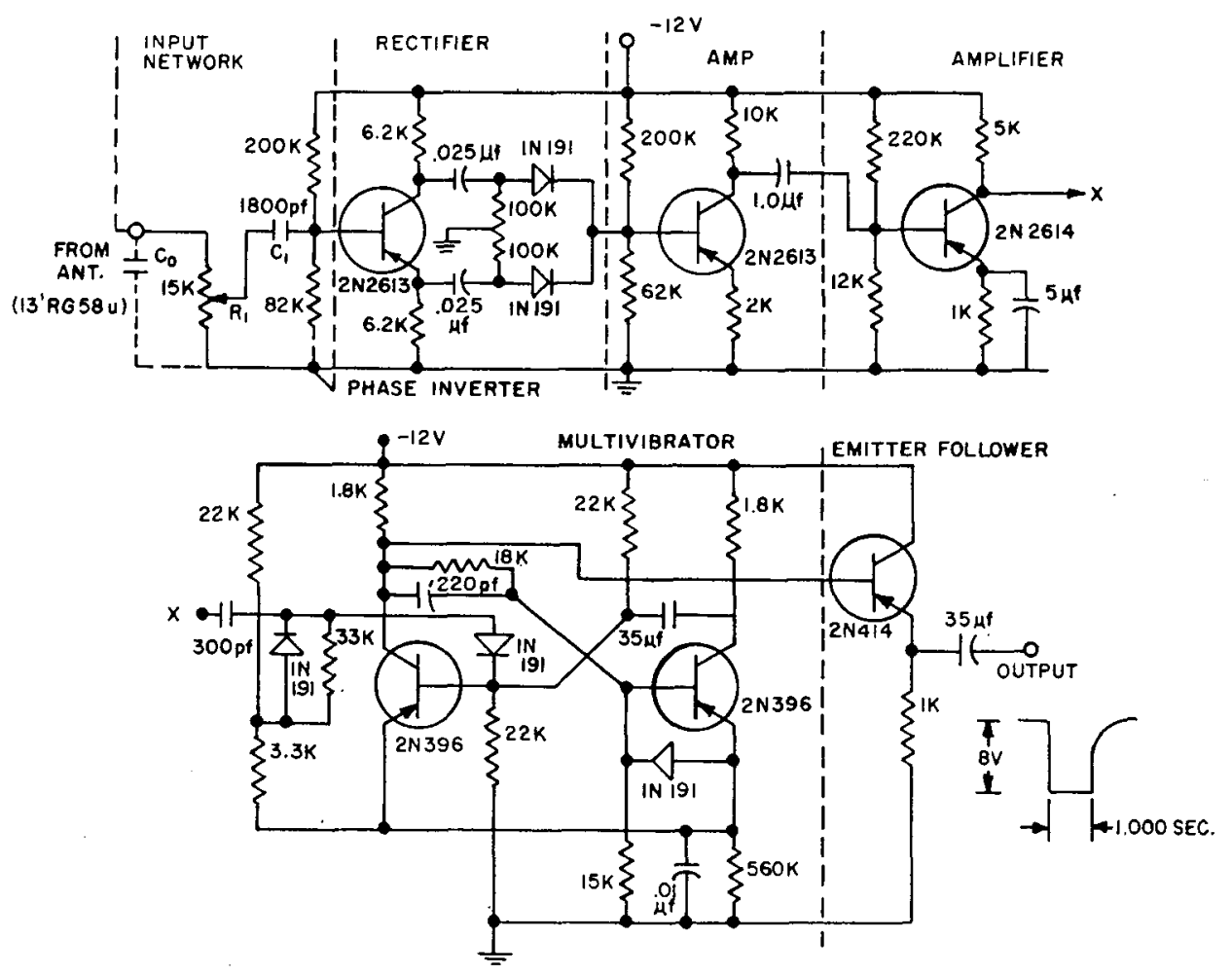

FIG. 2. Circuit diagram of lightning discharge counter.

A ball antenna of 4 inches in diameter, placed on the end of a nonconducting rod, was used to extract energy from the changing electric field caused by a lightning discharge. The magnitude of the induced voltage will depend upon the height of the ball above earth ground. Because of its small capacitance, the ball antenna differentiates the induced voltage. The input voltage to the counter resulting from a generalized concept of an electrostatic field change of Fig. 1a is shown in Fig. 1b.

The basic concept of the Sullivan-Wells counter was followed in this instrument. The voltage pulses received irom the ball antenna are rectified, amplified, and used to trigger a monostable multivibrator. A pulse from the multivibrator is an indication of a lightning discharge and can be used (with appropriate circuitry) to trigger a counter or recorder.

From a consideration of typical rise times and of the

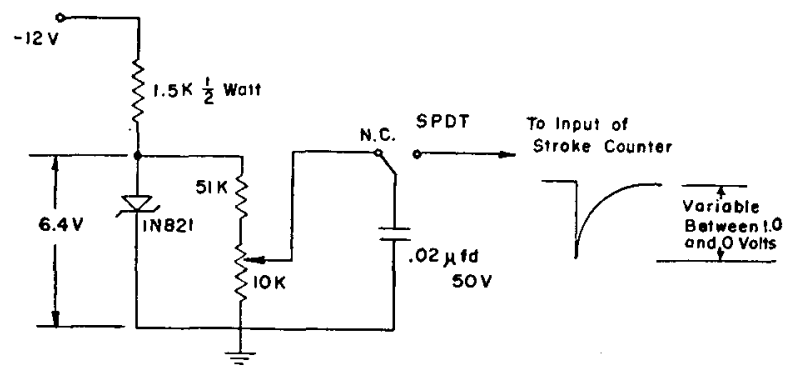

FIG. 3. Calibration circuit of lightning discharge counter. energy distribution of cloud-to-ground lightning discharges, the bandwidth of the counter was chosen to be $1.6-40 \mathrm{kHz}$ at the $3-\mathrm{db}$ points.

Since positive or negative field changes will arrive at the antenna, depending upon the type of lightning discharge and the distance of it's dipole (a mirror image discharged to ground of an assumed vertical dipole for intra-cloud discharges) from the antenna, a full-wave rectifier is used in conjunction with the multivibrator network for complete acceptance. A high grade mica capacitor is used for $\mathrm{C}_{1}$, to isolate the input from the high electrostatic fields present during a storm (Fig. 2).

To insure that the counter registers only one count for each complete lightning discharge (see Section 3), a 1 -sec pulse width was chosen for the multivibrator. Therefore, if a lightning discharge does not have a total duration $>1 \mathrm{sec}$, then only one count will be registered, no matter how many discrete field changes are contained within the discharge. The counter response to a typical discharge is shown in Fig. 1c., assuming that the counter is triggered on the second pulse of Fig. 1b.

\section{b. Calibration circuit and readout design}

The calibration circuit is similar to that used in the original Sullivan-Wells design. The circuit diagram and pulse characteristics are shown in Fig. 3.

The appropriate counter readout design will be dictated by the use to which the data will be put, providing it accepts the counter's output characteristics (Fig. 4). 


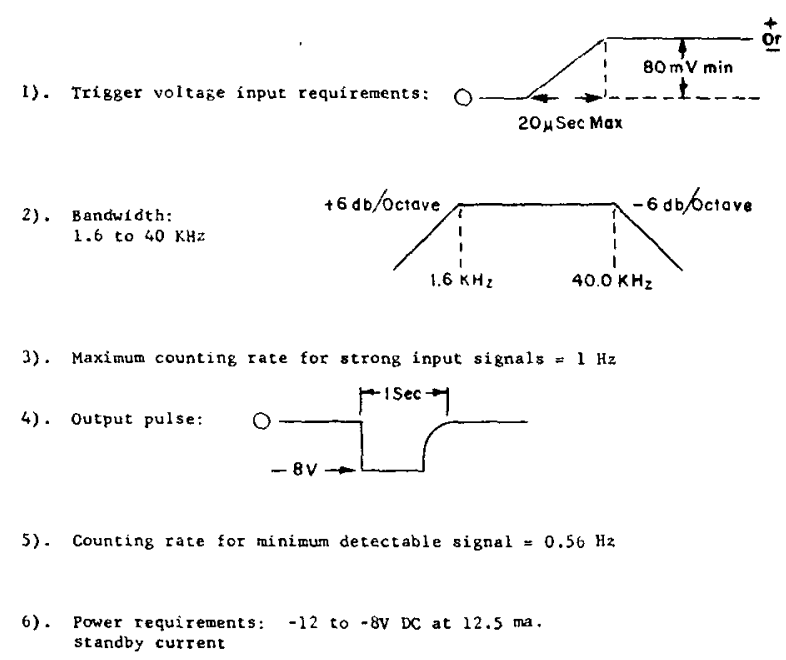

FIG. 4. Electronic test characteristics for a transistorized lightning discharge counter.

\section{Experimental procedure}

The configuration illustrated in Fig. 5 was used in the testing program of the counter. The antenna was installed on a high point of the roof (a convenient location situated about $40 \mathrm{ft}$ above earth ground) of Building \# 56, on the Naval Observatory Reservation in northwest Washington, D. C. The counter chassis was connected to a good earth ground and approximately $130 \mathrm{ft}$ of shielded coaxial cable was used to bring the negative pulse from the counter into the laboratory.

Recorder No. 1 diagrammed in Fig. 5 was an Esterline-Angus event recorder with a chart drive of 3 inches $\mathrm{hr}^{-1}$. This recorder was on continuously during the summer of 1965.

Recorder No. 2 was a Brush Instruments "Mark II" paper recorder. This instrument time-resolved the periods of intense stroke activity. Finally, the counter pulse was fed to an electronic counter.

\section{a. Multiple stroke problem}

In order to verify that the counter was not registering multiple strokes, the pulse width of the multivibrator was changed to that of the original Sullivan-Wells counter $(\sim 0.2 \mathrm{sec})$. Lightning discharges from a thunderstorm at 2130 EDT 8 August 1965 were recorded on the Brush recorder. These discharges were also recorded by an independent system consisting of a simple ball antenna connected to the microphone input of a portable UHER, model 4000S, magnetic tape recorder. The sferic signals on the tape were later transformed into visual information by a MinneapolisHoneywell "Visicorder" oscillograph. Each discrete field change within a discharge was resolved by the tapeoscillograph combination. A discharge appeared on the oscillograph paper (Fig. 6) as an isolated burst of

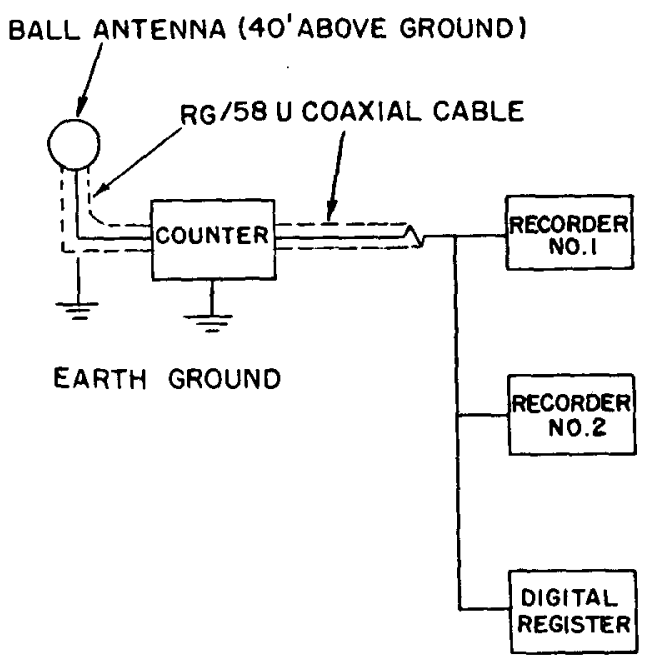

Fig. 5. Test configuration of the lightning discharge counter.

spikes. This record was compared with the stroke record from the transistorized counter and it showed that the counter would register up to 4 strokes from one discharge, depending on the discharge duration. Good time correlation between a field-change spike and a stroke indication by the counter within a single discharge was achieved. Thus, it is concluded that multiple counts did arise from the 0.2 -sec pulse width counter being activated by individual field-change steps within a single discharge. The same experiment was performed during another storm at 1800 EDT 18 August 1965. However, for this storm the multivibrator pulse width of the transistorized counter was changed to $1.0 \mathrm{sec}$. Good correlation between the signals on tape and the counter output was obtained, and no multiple counts were detected as indicated in the lower part of Fig. 6. More than $90 \%$ of lightning discharges have durations $<1 \mathrm{sec}$ (Schonland 1953, Brook and Kitagawa 1960a) and we found that they rarely occur faster than one per second for the entire thunderstorm. Therefore, a pulse width of $1 \mathrm{sec}$ should be adequate to give an accurate statistical representation of thunderstorm activity.

The bandwidth of this counter is such that it responds more readily to cloud-to-ground discharges than to intracloud discharges. However, as a storm moves

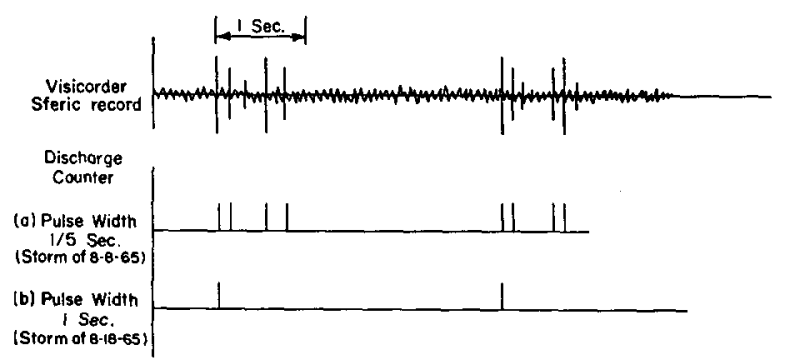

FIG. 6. Typical response to lightning discharges for two values of multi-pulse width. 
closer to the counter the intracloud discharges will also register because there is sufficient energy in the lowfrequency part of the spectrum of nearby intracloud discharges to trigger the counter. From our studies and those of Kinzer (private communication), it has been shown that there are approximately three times as many intracloud as cloud-to-ground discharges in a typical storm; as the storm moves overhead the counter will register practically all discharges. The rate of intracloud and cloud-to-ground discharges given about is truly approximate, since in any instance the storm under investigation might consist solely of intracloud discharges or only cloud-to-ground discharges. It would be difficult, if not impossible, to design a counter that would respond only to cloud-to-ground discharges for all storm locations and types. However, while the transistorized counter does not give an accurate determination of the number of cloud-to-ground discharges, it does give a relative indication of the severity of the storm, as it is certain that a high percentage of the counts registered correspond to one complete discharge.

\section{b. Temperature effects}

Temperature effects on the instrument were studied by placing the counter in an environmental chamber. The sensitivity was found to decrease $7 \%$ from an arbitrarily selected value at $20 \mathrm{~F}$ (as tested by the calibration circuit) when the temperature was raised to $130 \mathrm{~F}$. This change can be compensated by a slight adjustment of the calibration circuit as the need arises.

\section{c. Power supply}

The counter was designed to operate on $12 \mathrm{~V}$ dc. Line surges caused by the switching on and off of motors or other large inductances were held to a tolerable 6 counts day ${ }^{-1}$ with the counter sensitivity set so that the counter triggered for a $250-\mathrm{mV}$ pulse. The calibration circuit will operate with a battery voltage as low as $8 \mathrm{~V}$. Stand-by power supply current drain is approximately $12 \mathrm{~mA}$.

\section{d. Sensitivity Test}

The maximum range for our counter, with the experimental conditions described previously, was determined by comparing those storms which registered one count per minute with the counter at full sensitivity, against radar records obtained by the WSR -57 radar located at Washington National Airport. Eventually, data were collected from several storms during which both the radar and the counter were operating simultaneously. These storms are listed in Table 1.

It is evident that the normal maximum detection range of the counter for the antenna used is approximately $80 \mathrm{mi}$, assuming an average radiated power density for a typical cloud-to-ground discharge dissipating $20 \mathrm{C}$. However, at this range the counter is
TABLE 1. Range data of some selected Washington, D. C., area thunderstorms for August 1965.

\begin{tabular}{|c|c|c|c|}
\hline Date & $\begin{array}{c}\text { Time } \\
\text { (ED'T) }\end{array}$ & $\begin{array}{c}\text { Radar } \\
\text { azimuth }\end{array}$ & $\begin{array}{c}\text { Distance } \\
\text { from } \\
\text { counter } \\
\text { for } 1 \text { count } \\
\text { min }^{-1} \\
(\mathrm{mi})\end{array}$ \\
\hline 8 August 1965 & 1808 & $320^{\circ}$ & 60 \\
\hline 9 August 1965 & 1245 & All & 60 \\
\hline $\begin{array}{l}10 \text { August } 1965 \\
17 \text { August } 1965\end{array}$ & $\begin{array}{l}1930 \\
1440\end{array}$ & $\begin{array}{l}\text { directions } \\
122^{\circ} \\
-\end{array}$ & $\begin{array}{l}87 \\
70\end{array}$ \\
\hline
\end{tabular}

registering the radiation field associated with cloud-toground and perhaps the more intense intracloud discharges.

The range can be shortened to any desired distance by adjusting the sensitivity potentiometer. The counter can be calibrated to detect storms at a specified radius by locating a storm at the desired distance and adjusting the sensitivity control until counts just begin to register. The calibration voltage should be set so that the counter just begins to register when the calibrate button is pushed, since this determines the level of reference voltage needed for recalibration at some future date.

After five months of operation, no appreciable change in maximum sensitivity was observed (i.e., an $80-\mathrm{mV}$ pulse amplitude triggered the counter with the battery voltage maintained at $12 \mathrm{~V}$ ).

\section{Conclusions}

The tests indicate that the transistorized counter is effective as a detection device at ranges of 70 or $80 \mathrm{mi}$. The counter gives a good indication of thunderstorm activity within a specified radius. The unit is virtually maintenance free. The initial objectives of our counter design, the elimination of multiple counts, and increased reliability have been fulfilled.

Temperature effects are minimal for this transistorized design.

The counter will produce only an index of relative thunderstorm activity for a given location, since it is unable to differentiate between intracloud and cloud-toground discharges of a nearby storm, or, for that matter, between distant intense cloud-to-ground discharges and relatively weak nearby discharges.

These limitations have been discussed previously (Brook and Kitagawa, 1960b) and caution must be observed in evaluating the absolute discharge count as detected and displayed by this instrument. However, this is irrelevant if only relative storm activity is desire.

The receiver as illustrated in Fig. 2 seems best suited as an inexpensive (under $\$ 20$ ) device for gathering thunderstorm data for Automatic Remote Weather Stations. 
Acknowledgments. We gratefully acknowledge the guidance given us during many discussions by Dr. G. D. Kinzer of ESSA's National Severe Storms Laboratory, Norman, Okla.

\section{REFERENCES}

Brook, M., and N. Kitagawa, 1960a: Some aspects of lightning activity and related meteorological conditions. J. Geophys. Res., 65, 1203-1210.
lightning-flash counters. J. Geophys. Res., 65, 1927-1931.

Schonland, B. F. J., 1953: Atmospheric Electricity. London, Methuen and Co., Ltd., p. 61.

- 1956: The lightning discharge. Handbuch der Physik, Vol. 22, Berlin, Springer-Verlag, 576-628.

Sullivan, A. W., and J. D. Wells, 1957: A lightning stroke counter. Bull. Amer. Meleor. Soc., 38, 291-294.

Zegel, F. H., 1964: Lightning stroke counters. Meteor. Eng Rept. No. 10, U. S. Weather Bureau, ESSA.

_-, 1967: Lightning deaths in the United States: A seven-year survey from 1959 to 1965 . Weatherwise, 20, 168-173. 